\title{
Querying medical and legal discourses of queer sexes and genders in South Africa
}

\author{
By Thamar Klein (Max Planck Institute for Social Anthropology)
}

South Africa is one of the most progressive countries worldwide regarding the rights of people with variations of gender identity and/or sex development. This paper queries medical and legal discourses of queer sex and gender. It takes a look at the medico-legal discourses on people whose identities and/or bodies exist outside of the binary of male and female or transition within this binary in South Africa.

South Africa has come a long way concerning the biomedical and legal treatment of what I would like to call (following Diamond and Beh 2006) variations of gender identity (in medical literature often categorised as transgenderism, transsexuality, gender dysphoria, or gender identity disorder) and variations of sex development (also known as intersexuality, hermaphroditism or disorder of sex development). Many LGBTTIQactivists consider the country to be, from a legal point of view, among the most progressive worldwide. Its laws are very advanced with regard to the legal emancipation of people encompassed under the acronym LGBTTIQ: Lesbian, Gay, Bisexual, Transsexual, Transgender, Intersex, and Queer. South Africa's laws are also advanced with regard to the possibility of applying for legal adjustment of one's sex description without genital surgery (as described in detail in the section on medico-legal discourses below). Nevertheless people with variations of gender identity and/or sex development, as well as many of the medical specialists treating them, still face a vast array of obstacles and deal with divergent discourses. In this paper I look at the South African history of medico-legal discourses and compare the current medical situation of people with variations of sex development to that of people with variations of gender identity.

I start with a brief overview of the definition of "queer" as used in this paper. I proceed by offering a brief overview of the background of my research, as well as methodology and research sites. I then move on to a discussion of the South African juridical and medical situations of people with variations of gender identity and/or sex development from the beginnings of legislated Apartheid until today (1948-2008). The time frame has been chosen due to the significant legal changes that have taken place during this period with respect to the research question. The last section interrogates and compares the current medical situation of people with variations of sex development to that of people with variations of gender identity. 


\section{Introduction: queer}

"Queer" has a range of diverse meanings, especially in cross-cultural settings. Let me therefore clarify the use of this term for the purpose of my paper. "Queer" here signifies a critical position towards binary oppositions especially, but not exclusively, in the area of sex, gender and sexuality. I have chosen the term "queer" because of its deconstructivist praxis and its likewise inclusive qualities. "Queer" questions silent background norms and looks into the construction of normality (see for example Warner 1999). Furthermore, those who are excluded from or fall outside these norms and normalities are made visible. The term's inherent enquiry for the excluded and its radical ambiguity permits an inclusion not only of a huge variety of gender and sexual identities, but also suspends discrimination on whatever grounds, e.g. skin colour, class, age, religion, health, language, and so on. For a discussion of compulsory able-bodiedness and queer theory see for example McRuer (2006); for an exploration of the interrelationships of gender, class, race and ethnicity and other social divisions see Yuval-Davis (2006). As Cheryl Chase puts it, "The value of the word 'queer' is that it talks about difference that's stigmatized or transgressive without defining exactly what that difference is" (Hegarty 2005:79).

Thus it permits me to look at people who are classified as e.g. transgendered or intersexed (by themselves, the legal and/or the medical system, or anybody else) not simply as a group, but as individuals with distinct experiences that shape their bodies as well as their identities and that put certain things and possibilities within or beyond their reach. Ahmed (2007:159) states - when writing about the phenomenology of whiteness that "how we inhabit a certain category depends on how we inhabit others". This is certainly also true with regard to people with variations of gender identity and/or sex development. The interaction and intersectionality (the ways in which different social partitions are enmeshed; Crenshaw 1989) of various socially and culturally constructed categories leads to very different levels of (in)equality in society, and can make a huge difference in one's ability to access knowledge, medical assistance and legal help. Even though people with a queer sex and/or gender are often discussed as a single group, the complex intersectionality of e.g. class, religion, ethnicity, skin colour, income, and so on, places individuals at very different positions in life and lets them inhabit a single category in various ways.

Let me illustrate this briefly through a few examples. The economic divide (still very attached to the racialised divide) plays an important role concerning access to information and body alteration. People who come from disadvantaged economic backgrounds have difficulties getting in touch with NGOs (Non-Governmental Organisations), NPOs (NonProfit Organisations), and other organisations catering for them. This is in part due to the fact that the internet seems to play a very important role. Most of my interviewees with variations of gender identity who had access to the internet stated the importance of it:

While I was still working for [...] I got access to the internet. [...] I just typed in "men dressing as women". Because I had no idea what, what I was or anything, all I knew is, I had this thing that I felt feminine and I felt like I was a woman but... although the only way I could express it was in the way that I was dressing. So I put in the search and it came back with a whole lot of different things. Hmm, uh, yeah, results and I started reading some of them and for the first time I started discovering 
that I'm not the only person in the world who's doing these kinds of things. I hadn't met anybody before that. (Anonymous interviewee, 10 September 2007)

However, the internet is only available to a very limited extend to people living in South African townships (or on the street). Transport to social gatherings is equally difficult for them in the evening hours (when most social gatherings take place) as there is no public transport to and from the townships at night.

Because [pause] the people that, the others that society will call coloureds or blacks; because there's most of them that don't have internet access and stuff or how to get to socials and stuff like that, that is why you don't really see them, but... and the so called white community is; they are more visible because they've got more monies as well. (Anonymous interviewee, 24 September 2007)

Access to biomedical care and body-altering products also depends to a great extent on financial resources. As a result of financial strain, general medical doctors or general practitioners (GPs) seem to be seen far more often for hormones, for example, than endocrinologists. Some GPs were said to be more "pragmatic", as they will do the blood tests and screenings when the client is able to pay (some even seem to work on credit). In contrast to endocrinologists, GPs were said to cater for people with variations of gender identity with regard to their individual budgets instead of insisting on the "proper" biomedical order. Thus expensive blood screenings demanded by endocrinologists in order to be able to prescribe hormones or adjust the dosage of hormones can be avoided or postponed. Furthermore many of the MtF (Male to Female) interviewees with low or no income stated that they had tried to gain access to birth control pills instead of (or after unsuccessfully) seeking admittance to biomedical supervised hormone treatment. Contraceptive pills are available free of charge at public sector family planning clinics. However they are only given to cis-women and not to MtFs. (The Latin prefix cis stands for "on the same side", whereas the prefix trans stands for "on the opposite side". "Cisgendered" or "cissexual" describes people whose gender identity matches their perinatally assigned sex.). Thus the interviewees were dependent on cis-gendered women (and sometimes FtMs who could still pass as women) for help as long as they were not able to pass as cis-women themselves. The contraceptive pill is moreover popular with transwomen as it is said to cause a greater increase in breast size than the hormones available at GPs and endocrinologists. These are but a few examples of how the economic divide, which is still closely aligned with the racialised divide, places individuals at very different positions in life.

Intersectionality is also important in the way it shapes the possibilities of living out one's identity and giving it a name. For example, Donham (2002), who did research on gay identity in South Africa, states that in the 1960s and 70s feminine urban black South African men were considered to be women (or intersexed) and their partners heterosexual men. In academic discourse they might be termed wo_men. I use the underscore character in this context to visualise the interstitial spaces between the binary categories of man and woman that become highly visible in this example. (The underscore character has become more and more popular in German language as a step in the direction of gender-neutral language and an attempt to work against a linguistic consolidation of the gender-binary, and in order to make people with variations of gender identity or variations of sex development visible, who were rendered invisible through a highly 
gendered language; cf. e.g. Balzer et al. 2007 and Eder 2007.) It was only through awareness of a global gay community that these lives were re-categorised - instead of woman and man they were understood to both be homosexual men. To illustrate this, Donham quotes some of these wo_men who reported that they became aware of a global gay community through their work in the hotel industry or through closer contact with white gay men. In those contexts, both partners were classified as male and thus as gay and not heterosexual: "gay identity meant literally a new gender and a new way of relating to his body [...] '[...] Before, I thought I was a woman. Now I think I'm a man' (quoted in McLean and Ngcobo 1994:168-9)" (Donham 2002:420). Thus the enmeshment of different socially constructed divisions (the intersectionality) of sexual orientation on the one hand and race on the other hand led during Apartheid to very different gender identities.

A similar experience of shifting identity over time was related to me by one of my interviewees:

Because I actually started to look at guys. So, I thought actually that I was gay. Because every guy that looks at a guy is obviously gay, right. [...] I actually went to gay groups. But I didn't fit in! I didn't fit in! Ya, so when I discovered the term transgendered, I thought actually “ok, and I am now looking at men but men don't want me! So I can actually go for women as well and that would make me lesbian. Cool!" So, that didn't work out actually [...] Ya, and then I tried the... heterosexual... again... that's plain boring. So I don't want to be anything. [...] I just want to be me that fell in love with people, not genitals. Ya... No, I really don't want to put myself in a box. Not anymore. [...] I don't wanna be anything. But I mean I'm female. I present myself as female. But I've got a dick. I don't want "guy" attached to me. [...] I like being me. [...] I just wanna be me. "Chick with a dick" that's like, that's the closest that I can describe myself. The closest. Not really, but the closest. (Anonymous interviewee, 24 September 2007)

The interviewee's repeated exclamation "I didn't fit in!" illustrates why I have chosen the term "queer": not because people necessarily identify themselves in this way, but because of the term's encompassing, inclusive and ambiguous qualities. Many in fact do not identify with the word, since in a vernacular South African context it is interpreted as white male homosexuality. I use "queer" here as an interim provisional term - a blank space for many different identities; simultaneously keeping in mind that the term questions the naturalness and universality of identities (cf. Wilchins 2004). I use it to avoid the overly narrow and often pathologising Western medical definitions of gender identity disorder/transsexuality/gender dysphoria and disorder of sex development/intersexuality/hermaphroditism (though I will return to this medical vocabulary below when examining the South African medical and legal settings). Many South Africans may actually neither have heard of these labels nor used them as a signifier of some aspects of their identity. Instead I use "queer" as a blank space in order to avoid excluding people who will not come into contact with medical and/or legal professionals in South Africa even though their bodies or gender identities diverge in one way or another from the binary-cis-sex/gender-model or transition within this binary. 


\section{Research background and methodology}

The research for this article was carried out as a member of the project "Biomedicine in Africa", organized by the Max Planck Fellow Group Law, Organisation, Science and Technology at the Max Planck Institute for Social Anthropology. My research project Que(e)rying Sex and Gender in South Africa examines medico-legal practices and discourses in South Africa. It is a science and technology study exploring a specific section of the broad subject of the medicalised body. As part of my current work on medical, legal, and political discourses on gender and globalisation, I query the relationship between medicine and queer bodies in South Africa. My project takes place at the intersections of the production of scientific medical knowledge, the use of this knowledge by diverse stakeholders (e.g. political, religious, legal, activist, etc.), medical work, people's personal perceptions of their bodies with regard to their gender, and their agency in altering their bodies. In this paper, however, I will focus on medico-legal discourses on people whose identities and/or bodies exist outside of the binary of male and female or transition within this binary in South Africa.

I have chosen South Africa as a research site for the reason that the juridical situation of persons with variations of gender identity and/or sex development in this country has changed significantly since the beginning of the Apartheid era in 1948. Owing to the Apartheid struggle, in 1996 South Africa became the first country with a constitution that protects people from discrimination on the grounds of sex, gender and sexual orientation. Another important example of South Africa's unique legal approach to gender identity was the implementation of The Alteration of Sex Description and Sex Status Act, No. 49 of 2003 (which came into effect in 2004). Through it, it became possible to apply for legal adjustment of one's sex description without genital surgery. These legal changes are especially interesting since there is a considerable gap between the progressive legal code and, in this respect, the much more conservative South African society. Even the Department of Home Affairs - where the appeals for Sex Description Application have to be processed - still only issues documents after completed genital surgery and demands letters from the surgeons who carried them out (De Vos 2007, and Liesl Theron, pers. comm., 24 February 2007). Thus the Department of Home Affairs fails to implement The Alteration of Sex Description and Sex Status Act.

This article draws mainly on data from 65 semi-structured interviews, of between 30 and 150 minutes in length, conducted in 2007 and 2008 in Cape Town, Pretoria, Johannesburg (and Soweto) with surgeons, endocrinologists, clinical social workers, sexologists, psychologists, legal specialists, activists, and persons with variations of gender identity and/or sex development. Many of the medical experts are working in both private and public practice. Additionally I have included some information from medical and legal literature, participant observation, and observation without participation.

Due to the difficulties in accessing not only persons with variations of gender identity and/or sex development but especially medical experts working in this sector, interviewees were selected by snowball sampling. Most interestingly, even though there is very little information available on the internet, it offers much more information on NGOs and social and support groups than on medical specialists in South Africa. Neither the specialists working in the public sector nor private sector are formally organised into a professional organisation or an interest group. I am aware that snowball samples are 
subject to numerous biases. As the group of medical specialists in the public sector seems to be rather small, however, and as the research is still underway, I hope that I will eventually be able to locate all the public sector medical specialists involved.

\section{Medico-legal discourses}

It is interesting to note that the current rights of people with variations of gender identity and the rights of people with variations of sex development were not secured simultaneously. In 1996 South Africa was the first, and is still the only, country worldwide to enshrine the rights of persons with variations of gender identity in its Constitution. Thus it is the only country that - at least nominally - protects people with variations of gender identity to the full extent. The rights of people with variations of sex development, however, were first explicitly secured through an amendment of section 1 of Act 4 of 2000 (the PEPUDA also known as Equality Act: Promotion of Equality and Prevention of Unfair Discrimination Act) in January 2006. A statement saying that the term "sex" includes intersex and a definition of intersex were inserted through the amendment. It is, in fact, only from that time on that the Constitution has afforded guaranteed protection in law to people with variations of sex development. It has to be noted, however, that this protection is still in its initial stages of implementation. The vulnerability of people outside the binary-cis-gendered/sexed system remains very high. Even though people with variations of sex development are protected through the Constitution - as the term "sex" in the Equality Clause now includes intersex by statutory stipulation - no certificates or legal documents are issued stating that intersex is the legal sex of a person.

The following legal history similarly reflects the hesitation to cater specifically to the rights of intersexed persons and reveals a rather one-dimensional focus on transsexuality. The Birth and Deaths Registration Act of 1963 allowed transgendered persons to apply to have their sex status changed in the birth register after sex reassignment surgery. This was changed in 1992 by the introduction of section 33(3) into The Birth and Deaths Registration Act, which stated that only persons who had commenced sex reassignment prior to 1992 could apply. Accordingly only ongoing transitions could be finalised but none could be initiated. As a consequence, nobody could legally start transitioning after 1992 to have the sex status adjusted in their documents. This decision was apparently based on a court case from 1976 "where the court held that a person's sex could not be medically changed” (SAHRC 2003:2).

The central question in the case was whether it was possible for a person to change their sex (as defined for the purposes of marriage). In deciding that it was not, the court employed the so-called "Ormrod Test", from the English Case of Corbett $v$ Corbett (1971). This amounts to a purely biological and genetic definition of sex. It looks to "chromosomal, gonadal and genital tests" and if all three are congruent determine(s) the sex for the purpose of marriage accordingly and ignores any operative intervention. In other words, a person's sex for legal purposes is a wholly biological question and is fixed at birth. (SAHRC 2003:2) 
Thus the legal understanding of sex which had previously included psychological and social aspects was reduced to chromosomal, gonadal and genital differentiation at the time of birth.

What actually led to this decision is unclear. The explanation given above seems rather unsatisfying as there is a gap of 18 years between the court case and the amendment in The Birth and Death Registration Act. Moreover this modification was made after there had been quite a peak of sex reassignment surgeries and newly issued birth certificates in the 1980s - and sex reassignment surgeries had already been carried out regularly previously. According to the South African Law Commission, 150 transsexuals were treated between 1969 and 1984 at Groote Schuur Hospital in Cape Town alone (South African Law Commission 1995:8). Crichton (1993:347) states that he carried out 58 surgeries at the University of Natal Hospital in Durban between 1969 and 1993. (By way of comparison, Conway [2002] gives the following estimates of $\mathrm{MtF}$ sex reassignment surgery operations among US residents: 1960s: 1,000; 1970s: 6,000-7,000; 1980s: 9,00012,000; 1990s: 14,000-20,000.) According to journalist Ana Simo:

former apartheid army surgeons estimate that as many as 900 forced "sexual reassignment" operations may have been performed between 1971 and 1989 at military hospitals, as part of a top-secret program to root out homosexuality from the service. (Simo 2000, emphasis is mine)

The same numbers are stated by forensic psychiatrist Robert Kaplan and journalist Paul Kirk:

Recurrent allegations have been made that between 1969 and 1987 approximately 900 men and women had gender reassignment surgery [...] They were given new identity documents, discharged from the military, and told to cut themselves off from family and friends. [...] The rationale for giving homosexuals reassignment surgery, in complete ignorance of the scientific literature on transsexualism, can only be described as repulsive. It was based on the simplistic belief that male homosexuals were sissies, female homosexuals were tomboys, and surgery would end their preference for the same sex by allowing them to fulfil their projected role in the opposite sex. (Kaplan 2004:1415-1416)

The exact number of conscripts who were involved is not certain, but surgeons told the Mail \& Guardian that about 50 sex-change operations were performed a year between 1971 and 1989. [...] In what was a top-secret project during the apartheid years, psychiatrists assisted by chaplains scoured each intake of national servicemen, hunting for suspected homosexuals. Those identified as homosexuals were quietly separated from their comrades and sent to ward 22 of Voortrekkerhoogte military hospital for screening and a programme of "rehabilitation". Some of those who could not be "cured" with drugs or psychiatry were given sex-change operations or were chemically castrated. (Kirk 2000)

Unfortunately most of the people who transitioned forcibly or voluntarily in the 1980s and earlier are neither available as historical witnesses nor as role models for the younger generations of people with variations of gender identity (which was regretted by some interviewees) as they were advised to leave the country or at least their home town after surgery, to break all ties with family and friends, and to live in stealth (Kaplan 2004:1415). In line with the government's desire at the time to make their transition invisible, all their newly issued documents were waiting for them when they left the 
hospital in order to be able to start their new life (Liesl Theron, pers. comm., 24 February 2007). Swarr however points out that "the ease with which transsexuals have changed identity documents has varied immensely in different time periods and regions of the country" (2003:77). This was also reflected in the interviews that I carried out: one interviewee had her new documents (birth certificate, ID-book, driver's licence and bank cards) issued without undue delay (Anonymous, 22 November 2007) while another had to wait for 16 months (Anonymous, 10 September 2007).

Thus, further explanation that might be related to the revision of The Birth and Death Registration Act are changes in the military system at the time. The universal conscription of white males into the military (1967-1991) ended in the year before the amendment of the Act went through. In order to understand the possible link between the end of universal conscription of white men (along with the resulting affiliated changes in the military) and the end of reassignment surgery at the closing stages of the Apartheid era, one has to be aware of the above mentioned "rehabilitation" programmes in the military that aimed to "cure" homosexual personnel and within which the forced surgeries took place. These atrocious "treatments" (without consent) and human rights abuses - including electric shock aversion therapy, psychiatric drug treatment, chemical castrations and sex reassignment surgery - seem to have been abandoned in the same time period (for a more thorough discussion, see Kaplan 2004, Kirk 2000, Van Zyl et al. 1999). Whether (and to what extent) there is a connection between the simultaneous ending of the experimental sex reassignment surgeries and other repulsive treatment of homosexuals in the South African Defence Force with the ending of universal conscription for white males into the military and the introduction of section 33(3) into The Birth and Deaths Registration Act still needs to be investigated.

Even though sex, gender, and sexual orientation were included in the Equality Clause of the Interim Constitution of 1993, this mere inclusion was not sufficient to enshrine the rights of persons with variations of gender identity. They were still not legally recognized and did not receive new documents, as only persons who had commenced sex reassignment prior to 1992 could apply. The same was true when the Equality Clause in the Bill of Rights of South Africa's Constitution (as Section 9 (3) is called) came into effect in 1996. As in the Interim Constitution of 1993, it prohibited discrimination on the grounds of sex, gender and sexual orientation, but stated that only ongoing transitions could be finalised and nobody could legally start transitioning. Thus in 1996 South Africa became, on the one hand, the first country to enshrine the rights of persons with variations of gender identity and/or sex development in its Constitution, while on the other hand it discriminated against them as in the amendment of The Birth and Deaths Registration Act of 1992. It only recently became possible to apply for the legal adjustment of one's sex description, due to The Alteration of Sex Description and Sex Status Act, No. 49 of 2003 (which came into effect in 2004).

The preliminary Alteration of Sex Description and Sex Status Bill compiled by the South African Law Commission - which laid the foundations for The Alteration of Sex Description and Sex Status Act - also failed to protect the rights of persons with variations of gender identity and/or sex development. Due solely to improvements and corrections inserted by a small number of people on behalf of the Human Rights Commission, the Cape Town Transsexual/Transgender Support Group, and by activist 
Sally Gross (working for ISSA: Intersex South Africa) on behalf of intersexed people, the Act now conforms to a large extent with the Constitution.

On the grounds of the aforementioned intervention came another important legal change with The Alteration of Sex Description and Sex Status Act: genital surgery was no longer required for the alteration of one's sex description. Nevertheless, a report from a medical practitioner is still mandatory. Opportunely the term "medical practitioner" was defined in such a broad way that it can include both biomedical therapists as well as so-called "traditional health practitioners". (The term traditional is highly and rightly contested within medical anthropology as it indicates a static or ahistoric practice. I am nevertheless using the term in this context as it is the official term used in the Traditional Health Practitioners Act of 2004.) However, as mentioned above, the Department of Home Affairs - where the appeals for Sex Description Application have to be handed in - still only issues documents after completed genital surgery and demands letters from the surgeon who carried it out, even though The Alteration of Sex Description and Sex Status Act explicitly states that:

2.(1) Any persons whose sexual characteristics have been altered by surgical or medical treatment or by evolvement through natural development resulting in gender reassignment, or any person who is intersexed may apply to the Director-General of the National Department of Home Affairs for the alteration of the sex description on his or her birth register. (Government Gazette 2004:30, emphasis is mine)

Sexual characteristics are defined by the Act as "primary or secondary characteristics or gender characteristics" whereas gender characteristics "means the ways in which a person expresses his or her social identity as a member of a particular sex by using style of dressing, the wearing of prostheses or other means" (Government Gazette 2004:30). According to The Alteration of Sex Description and Sex Status Act, the Department of Home Affairs may not reject applications from persons who choose surgery that does not involve primary sex characteristics or who choose hormone therapy without surgery. Theoretically any treatment by "traditional health practitioners" that has led to changes in the ways in which a person expresses his or her social identity as a member of a particular sex must be recognised as sufficient for the alteration of the sex description on his or her birth register. However this is not legal practice. The Department of Home Affairs is caught in a rather awkward position: it violates both the Equality Clause in the Bill of Rights and The Alteration of Sex Description and Sex Status Act. This must lead sooner or later to a court case if the Department does not abandon its current practice of demanding documents of completed genital surgery.

South Africa is, however, not the only country dealing with ambivalent agendas. It will be interesting to observe how perceptions of body, sex and gender will be debated in different social spaces as more and more countries pass or discuss laws regarding the definition of a person's legal sex as not relying on the look of that person's genitalia. Sharpe (2007) has dealt with a similar situation in Great Britain where the Gender Recognition Act of 2004 does not require surgery either, but where

it is clearly the expectation of the government that surgery will occur. [...] in the case of an applicant who has not undertaken surgery, the possibility remains [...] that this fact may hinder a diagnosis of gender dysphoria [which is essential for the legal adjustment of one's sex]. (Sharpe 2007:71-72). 
Currently the UK and Spain are still the only European countries where genital surgery is not a prerequisite for a new birth certificate in the lived gender. Permanent sterility remains a requirement for a new birth certificate in the lived gender - or at least the entry of the lived gender into the old birth certificate (a highly contested procedure since it fails to protect a person's privacy) - by Austria, Belgium, Denmark, Finland, France, Germany and the Netherlands. Genital surgery is required in Lithuania and secondary sex characteristics surgery is compulsory in the Czech Republic and Greece. The birth certificate cannot be changed at all in Ireland, Italy, Portugal, and Sweden (compare Whittle et al. 2008:22-23). But many NGOs - e.g. TransGender Europe, TransGender Netz Berlin (Germany), Crisalide-AzioneTrans (Italy), and Grupo de Identidad de Genero y Transsexualidad (Spain) - are fighting for the worldwide enforcement of human rights concerning the bodily and psychological self-determination and autonomy of people with variations of gender identity and variations of sex development. They question among other things the prerequisite of permanent sterility or surgery in order to change the sexentry in identity papers and on birth certificates to obtain full legal recognition.

\section{The current medical situation}

The South African Department of Health (2008) lists 381 public hospitals (in addition to more than 4,000 public clinics and community health centres). Of these 381 public hospitals only the 16 provincial tertiary hospitals and national central hospitals should be considered with regard to sex (re)assignment surgeries, as these surgeries can only be carried out at hospitals that provide Level III care which requires the expertise of clinicians working in recognised specialties and subspecialties. Surgery on people with variations of sex development is carried out in six of the 16 hospitals. These are Chris Hani Baragwanath Hospital (Soweto, Johannesburg), Groote Schuur Hospital (Cape Town), Johannesburg General Hospital, Pretoria Academic Hospital, Red Cross War Memorial Children's Hospital (Cape Town), and University of Kwa-Zulu Natal Medical School (Durban). This means that there are no facilities in two-thirds of the provinces for people with variations of sex development, namely the Northern Cape, North West, Limpopo, Mpumalanga, Free State, and Eastern Cape. Even fewer hospitals cater for the needs of people with variations of gender development. Gender variant people who were able to be classified as transsexual by a psychologist, in line with the World Professional Association for Transgender Health's Standards of Care for Gender Identity Disorders (formerly known as the Harry Benjamin International Gender Dysphoria Association's Standards of Care for Gender Identity Disorders, or simply as Standards of Care, SOC) will only be seen at two hospitals: Groote Schuur Hospital in Cape Town and Pretoria Academic Hospital.

In addition, there are budgetary restrictions which limit the number of patients that can be seen there. At Groote Schuur Hospital it was stated that they can only provide surgery for one FtM and one MtF per year. At Pretoria Academic Hospital one interviewee stated that they "can only do one full profile per quarter" (Anonymous, 28 November 2007). Thus waiting lists grow extremely long. Interestingly at both hospitals nobody was able or willing to let me know the length of the waiting list. As there is no publicly available statistical data on the prevalence of transsexuality in South Africa, it is hard to estimate the length of the waiting lists. There are however statistical figures from the Netherlands: 
Over the last 5 years [1990-1995] on average 50 (range 38-60) male-to-female transsexuals and 21 (range 14-25) female-to-male transsexuals received surgical and/or hormonal treatment yearly. (Van Kesteren et al. 1996:589)

One should keep in mind, though, that the population of the Netherlands is only about one third of that of South Africa - and that there might be waiting lists in the Netherlands as well. Thus the prevalence in South Africa should be approximately three times higher. Additionally it is quite interesting to note that at present the number of actually conducted reassignment surgeries has decreased to a rate that is significantly below the rate of surgeries carried out at the early stages of reassignment surgery in South Africa (cf. the figures mentioned in the section above on medico-legal discourses).

Even though all interviewees were quite anxious to point out that there were waiting lists and budgetary constraints for all kinds of surgery, they also stated that it was especially difficult to obtain theatre time and funding for sex/gender reassignment surgeries for people with variations of gender development.

For some people this is seen as non-essential surgery; for some people it is seen as hmm, as incorrect surgery. [...] It's not an ideological war against us; it's a budgetary war against us. (Anonymous, 28 November 2007)

Theoretically, surgery can be obtained in the private medical sector. Persons who are willing and able to pay for the much more expensive private care can visit any private clinic in and outside the country. The few services offered in the public sector are however of crucial importance to the vast majority of people. Since income is still intimately connected with gender and skin colour, the situation is especially difficult for persons who did not grow up categorised as white males - but private care is much too expensive even for many who have been categorised in this way. Two of my interviewees who were fortunate enough to be house owners sold their houses in order to finance their surgeries.

Besides the extremely limited numbers of patients who can be seen, the budgetary constraints in the public sector produce further restrictions for both patients and medical specialists. The latter have to work with limited theatre time and there is only a small team of medical experts available. Crucially there is only one psychiatrist available for the gender clinic at Pretoria Academic Hospital, and this psychiatrist only does private sector work, which is at the very least an astonishing fact for a public hospital. Especially as the - significantly higher - fees for the services of the psychiatrist have to be paid by the clients. Every patient at the gender clinic needs to be declared fit for surgery by this psychiatrist. As most clients come from various parts of the country and do not live in the direct vicinity of the psychiatrist, the travel time and money needed complicates regular visits and makes them unfeasible for many.

\section{Querying differences in the treatment of queer sexes and genders}

When querying sex and gender in the medical sector, I came across tensions between surgeons who perform operations on people with variations of gender identity and those who perform surgeries on people with variations of sex development. Even though most surgeons expressed their ability to perform surgeries for people with variations of gender 
identity and sex development, most surgeons only do surgery on either transsexual or intersexed people. Many expressed strong feelings against the other kind of surgeon and the surgery they carried out:

I mean I had [...] an adult male phone me and, you know he wanted a sex change operation. I mean he'd been counselled, he'd gone to the United Kingdom, he'd been to the United States, and he wanted it done in South Africa because he was a proud South African. He felt that the surgeons in South Africa could do it for him, you know, and uh, I mean you know we do the same operation, whether it's an intersex case or a transsexual case where the operation is the same but the philosophy behind the management of the patient is completely different. I declined to, to help him out; hmm, hmm because, you know surgery is not just the cutting, it's the overall care of the patient. (Anonymous, 27 November 2007)

Only a day later a surgeon performing surgery on transsexual patients repeatedly told me that he strongly opposes surgery on children with variations of sex development. Both surgeons questioned the ethics behind the other kind of surgery - the surgery that they did not perform.

Besides the general questioning of the ethics behind the respective surgeries, I found the double standard that some surgeons applied to the age of consent for people with variations of gender identity or sex development quite striking. One surgeon for people with variations of sex development was convinced that a 14 year old intersexed youth is able to give informed consent to surgery:

This is a little girl who was uh, uh a true hermaphrodite. [Showing surgical pictures] And she had grown up to, (that's a different problem) hmm, grown up to an age where she now wanted to be sexually active. She was [...] bisexual, but she wanted to have a normal female genotype. So she came to us after puberty and said, "These are what I want done". Okay, and we, uh....

Th. K.: How old was she?

She was about fourteen at this stage. And we then uh, operated on her [...] Hmm, and uh, and converted her to a normal female appearance. [...] Now that's the perfect situation. There you've got a person who has declared exactly what they want. They're of an age where they understand the implications of the operation, because [if] you take a tiny baby [...] that child is not [giving] informed consent. (Anonymous, 27 November 2007)

However, the same surgeon questioned the ability to give informed consent in a 16 year old transsexual youth:

No, I mean whether - I don't know about the ethics of, of medical practitioners assisting transgender, transsexual processes in people who are under-age. I worry about the ethics of that. I mean aren't you concerned about the ethics of 16 year olds, I mean because the brain in a 16 year old is a very, you know here today, gone tomorrow phenomenon. So I, I don't know, I don't think that a 16 year old has the capacity to take that sort of decision. (Anonymous, 27 November 2007)

All the surgeons I interviewed who perform surgery on children with variations of sex development stated that they have taken to wait as long as possible with surgery. This is a rather recent development that started around 2003/04 and that was initiated through the pressure from international groups such as ISNA (Intersex Society of North America). 
Then again one interviewee pointed out that as the pressure from parents is immense, however, surgery will in most cases take place around 3-6 months after the child is presented at the hospital. It is especially remarkable, bearing in mind the waiting lists for surgeries for people with variations of gender development, that the surgeries for people with variations of sex development can be performed so quickly.

In order to gain some sort of legal security the decision for surgery on infants and young people with variations of sex development in South Africa is taken as a team, where the team in most cases consists of a psychologist, an endocrinologist, the parents and the surgeon. In contrast to other countries where surgeons have been sued by their patients because the patients state that they were too young and ill-informed to give informed consent at the time of surgery, there have been no legal cases against surgeons of patients with variations of sex development in South Africa so far. This situation might change, however, as Yvette Abrahams, present Gender Equality Commissioner for the Western Cape, related to me that they have set up an "intersex group" at the Gender Equality Commission and are currently debating the illegality of cosmetic surgery on intersexed children with reference to the Constitution. (The Commission on Gender Equality is one of six state institutions supporting constitutional democracy. The aim of the Commission as set out in section 187 of the Constitution is to promote gender equality and to advise and make recommendations to Parliament or any other legislature with regard to any laws or proposed legislation which affects gender equality and the status of women.) As most intersexed patients are minors in contrast to transsexual patients, the surgery performed on them violates their right to choose their own sex and gender. Abrahams compared the practice to female genital mutilation. She pointed out that immediate surgery to alter genitalia of people with variations of sex development should be reserved for rare lifethreatening conditions and that most of the surgery carried out on infants is a cosmetic matter. However, this cosmetic surgery is said to be in the best interest of the child due to social norms that might result in social and psychological problems for the child at a later stage. Rebelo et al. (2008) argue that

Delaying genital surgery may be satisfactory in cases where the family and social dynamics are supportive of biological ambiguity, but in some cases we have found that indeterminate genital anatomy causes such distress to the family unit that early surgical intervention is requested by parents. (Rebelo et al. 2008:52)

Here it needs to be queried whether what is in the best interest of the family is truly in the best interest of the child.

\section{Conclusion}

Let me summarise and recapitulate the main points. In this article, I have outlined and queried the juridical and medical situations of people with a queer sex and/or gender from the beginnings of legislated Apartheid until today (1948-2008). The time frame has been chosen due to the significant legal changes that have taken place during this period. I have introduced the term "queer" because of its encompassing, inclusive and ambiguous qualities. At the same time I have pointed out that due to the intersectionality of a variety of culturally constructed categories, the experiences of individuals diverge widely: for 
example, the pressure for early surgery of infants with variations in sex development seems to be especially high from parents who live in townships (Rebelo et al. 2008).

"Queer" also questions silent background norms and looks into the construction of normality. Thus I was able to show that the silent background norm of a sex/genderbinary carries on despite the definition of intersex as a sex in its own right. No certificates or legal documents are issued stating intersex as the legal sex of a person. High uncertainty persists regarding how to deal with intersexuality as a sex in addition to male and female. The administrative process of stating the legal sex/gender within this sex/gender-binary remains very closely attached to the genitalia of a person. Even though genital surgery is no longer mandatory after 2004 in South Africa, the Department of Home Affairs - where the appeals for Sex Description Application have to be processed still only issues documents after completed genital surgery and demands letters from the surgeons who carried them out. Thus the Department of Home Affairs fails to implement The Alteration of Sex Description and Sex Status Act.

A further illustration of a de facto exclusion of queer sexes and genders while including them into the legal framework is the limited amount of resources given to public reassignment surgery of people with variations of gender identity. With regard to this point it has to be noted that there are diverging biomedical discourses and a double standard concerning the availability of surgeries and discussion of surgeries when comparing the situation of people with variations of sex development to that of people with variations of gender identity. The availability of surgery - and the pressure to conduct the surgery as soon as possible - is much higher for people with variations of sex development. It seems pertinent to ask if this is due to the fact that their queer bodies question the sex/gender binary to a greater extent. Surgery on their bodies restores the order of the binary. Physical bodies that question the sex/gender binary seem to be more difficult to accept than identities that question the sex/gender binary. The Department of Home Affairs' insistence on completed genital surgery seems to be accounted for by this phenomenon.

\section{References}

Ahmed, Sara. 2007. A phenomenology of whiteness. Feminist Theory 8(2), 149-168.

Balzer, Carsten, Lena Eckert and Jannik Franzen. 2007. Eine andere Wissenschaft ist möglich [A different science is possible]. Editorial. Liminalis 1, 1-5.

Conway, Lynn. 2002. How frequently does transsexualism occur? (http://ai.eecs.umich.edu/people/conway/TS/TSprevalence.html).

Crenshaw, Kimberlé W. 1989. Demarginalizing the intersection of race and sex: A black feminist critique of antidiscrimination doctrine, feminist theory and antiracist politics. University of Chicago Legal Forum 1989:139-167.

Crichton, Derk. 1993. Gender reassignment surgery for male primary transsexuals. South African Medical Journal 83(5), 347-349.

De Vos, Pierre. 2007. A man by any other name looks just as sweet... Constitutionally Speaking, 11 April 2007 (http://constitutionallyspeaking.co.za/?p=197). 
Diamond, Milton and Hazel G. Beh. 2006. Variations of sex development instead of disorders of sex development. Archives of Disease in Childhood. Electronic letter, 27 July 2006 (http://adc.bmj.com/cgi/eletters/91/7/554).

Donham, Donald L. 2002. Freeing South Africa: The "modernization" of male-male sexuality in Soweto. In The anthropology of globalization: $A$ reader (eds) Jonathan Xavier Inda and Renato Rosaldo, 410-427. Oxford: Blackwell Publishing.

Eder, Barbara. 2007. Unterstrich und Binnen-I: Vorschläge zu einer transgendergerechten Sprachpolitik. Unique-Magazin (http://www.univie.ac.at/unique/?tid=1528).

Government Gazette No. 26148. 2004. Alteration of Sex Description and Sex Status Act, 2003. Vol. 465, Cape Town, 15 March 2004 (http://www.info.gov.za/gazette/acts/2003/a49-03.pdf).

Hegarty, Peter in conversation with Cheryl Chase. 2005. Intersex activism, feminism and psychology. In Queer Theory (eds) Ian Morland and Annabelle Willox, 70-80. Basingstoke and New York: Palgrave Macmillian.

Kaplan, Robert M. 2004. Treatment of homosexuality during apartheid. BMJ (18 December) 329, 1415-1416.

Kirk, Paul. 2000. Mutilated by the military: Apartheid army forced gay soldiers into sex change operations. Mail \& Guardian, 4-10 August (http://www.geocities.com/crosswix/SOUTHAFRICA-3.htm).

McLean, Hugh and Linda Ngcobo. 1994. Abangibhamayo bathi ngimnandi (Those who fuck me say I'm tasty): Gay sexuality in reef townships. In Defiant desire: Gay and lesbian lives in South Africa (ed.) Mark Gevisser and Edwin Cameron, 158185. Johannesburg: Ravan Press.

McRuer, Robert. 2006. Crip theory: Cultural signs of queerness and disability. New York: New York University Press.

Rebelo, Ethelwyn, Christopher P. Szabo and Graeme Pitcher. 2008. Gender assignment surgery on children with disorders of sex development: A case report and discussion from South Africa. Journal of Child Health Care 12(1), 49-59.

SAHRC (South African Human Rights Commission). 2003. Submission, Alteration of Sex Description and Sex Status Bill [37-2003] (http://www.sahrc.org.za/sahrc_cms/downloads/Alteration\%20of\%20Sex\%20Des cription.doc).

Sharpe, Andrew. 2007. Endless sex: The gender recognition act and the persistence of a legal category. Feminist Legal Studies 15(1), 57-84.

Simo, Ana. 2000. South Africa: Apartheid military forced gay troops into sex-change $\begin{array}{llll}\text { operations. } & \text { TheGully.com, } 25 & \end{array}$ (http://www.thegully.com/essays/africa/000825sexchange.html).

South African Department of Health. 2008. Hospital list according to province (http://www.doh.gov.za/docs/tenders/hospitallist.pdf). 
South African Law Commission. 1995. Report on the investigation into the legal consequences of sexual realignment and related matters. Project 52.

Swarr, Amanda Lock. 2003. South African transgendered subjectivities: Exploring the boundaries of sex, gender, and race. Ph.D. Dissertation, Department of Gender, Women, and Sexuality Studies, University of Minnesota, Minneapolis, MN.

Van Kesteren, Paul J., Louis J. Gooren and Jos A. Megens. 1996. An epidemiological and demographic study of transsexuals in the Netherlands. Archives of Sexual Behavior 25(6), 589-600.

Van Zyl, Mikki, Jeanelle De Gruchy, Sheila Lapinsky, Simon Lewin and Graeme Reid. 1999. The aversion project: Human rights abuses of gays and lesbians in the SADF by health workers during the Apartheid era. Cape Town: Simply Said and Done on behalf of Gay and Lesbian Archives, Health and Human Rights Project, Medical Research Council, National Coalition for Gay and Lesbian Equality.

Warner, Michael. 1999. The trouble with normal: Sex, politics, and the ethics of queer life. Cambridge, MA: Harvard University Press.

Whittle, Stephen, Lewis Turner, Ryan Combs, Stephenne Rhodes. 2008. Transgender Eurostudy: Legal survey and focus on the transgender experience of health care. ILGA-Europe (http://www.ilgaeurope.org/europe/publications/non_periodical/transgender_eurostudy_legal_surv ey and focus on the transgender_experience of health_care april_2008).

Wilchins, Riki Anne. 2004. Queer theory, gender theory: An instant primer. Los Angeles: Alyson Books.

Yuval-Davis, Nira. 2006. Intersectionality and feminist politics. European Journal of Women's Studies 13(3), 193-209.

\section{Acknowledgements}

First, sincere and genuine thanks to the interviewees. I want to express my gratitude and appreciation for their important contributions, collaboration, time, and hospitality during my visits to their offices and homes. Special thanks go to Liesl Theron at GDX (Gender DynamiX, Cape Town), Sally Gross at ISSA (Intersex South Africa, Cape Town), and Anthony Manion at GALA (Gay and Lesbian Archives, Johannesburg) for their time, patience, and help. I am also very indebted to Caroline Bowley and Penny Morrell for their helpful comments on first drafts of this paper. Furthermore, the anonymous reviewers' comments, useful insights and suggestions greatly helped improve the article.

My gratitude and appreciation go to all the individuals, groups, institutes and organisations who contributed to this study directly or indirectly. Thanks to all.

\section{About the author}

Thamar Klein is a postdoctoral research fellow at the Max Planck Institute for Social Anthropology (Halle/Saale, Germany) and a member of the Research Group on Law, 
Organisation, Science and Technology. Extensive information on the current research project as well as on the author is available at www.eth.mpg.de/people/klein/index.html. The author can be contacted at klein@eth.mpg.de 